\title{
SISTEMA DE ACTIVIDADES METODOLÓGICAS, EN CONCEPCIÓN DE RED, PARA PERFECCIONAR LA PREPARACIÓN DE LA ASIGNATURA DIRIGIDA A LOS CONTENIDOS DE CÉLULA
}

\author{
AUTORES: Anabel Rodríguez Acevedo ${ }^{1}$ \\ Niurka Castillo Rocubert ${ }^{2}$
}

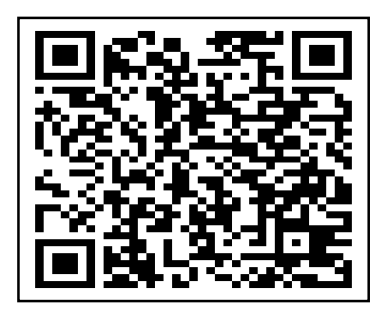

DIRECCIÓN PARA CORRESPONDENCIA: (aracevedo@nauta.cu )

Fecha de recepción: 17/05/2021

Fecha de aceptación: 22/12/2021

\section{RESUMEN}

En el trabajo se presenta una síntesis de las consideraciones acerca del trabajo metodológico, categoría que se introduce en nuestra práctica pedagógica a partir del proceso de perfeccionamiento de la educación que tiene lugar a partir del año 1975. El perfeccionamiento de la preparación de la asignatura en concepción de red, en los contenidos de célula es un proceso permanente que impone la necesidad de conocer el comportamiento del sistema y la proyección de las soluciones a los problemas encontrados en la preparación de cuadros y docentes, de manera ininterrumpida y sistemática. Elevar su calidad, exige tomar como punto de partida el desarrollo de investigaciones de carácter diagnóstico-pronóstico, que permitan conocer los rasgos más significativos de constatación de su estado como fenómeno investigado.

PALABRAS CLAVE: Trabajo metodológico; perfeccionamiento; preparación de la asignatura en concepción de red; contenidos de célula.

\section{SYSTEM OF METHODOLOGICAL ACTIVITIES, IN CONCEPTION OF A NETWORK, TO PERFECT THE PREPARATION OF THE SUBJECT AIMED AT CELL CONTENTS}

\begin{abstract}
In the work there is a synthesis of the consideration about the methodological work, a category that is introduced into our pedagogical practice from the process of improvement of the education that takes place from the year 1975. The improvement of the preparation of the subject in conception of the network, in the cell contents is a permanent process that imposes the need to know the behavior of the system and the projection of solutions to the problems encountered in the preparation of cadres and teachers, in an uninterrupted and systematic way. Raising its quality requires taking as a starting point the development of prognostic - diagnosis investigation, which

1 Universidad de Pinar del Río. Calle Martí No.272, Pinar del Río. Dirección postal: 20100. E-mail: aracevedo@nauta.cu.

2 Universidad de Pinar del Río. Calle Martí No.272, Pinar del Río. Dirección postal: 20100. E-mail: niurka.castillo@upr.edu.cu
\end{abstract}


allow us to know the most significant features of verification of its status as an investigative phenomenom.

KEYWORDS: methodological work; improvement; preparation of the subject in network conception; cell contents.

\section{INTRODUCCIÓN}

El trabajo metodológico se ha abordado de diferentes formas, de acuerdo a las etapas por la que ha transitado, tal como exponen resultados de investigaciones del Instituto Central de Ciencias Pedagógicas (ICCP, 2012). Desde 1977 hasta la actualidad se ha centrado en el desarrollo de actividades encaminadas a la superación profesional, ha estado dirigido a profundizar en el tratamiento de los componentes de la didáctica, en el perfeccionamiento de la preparación de la clase para favorecer, impulsar y estimular el trabajo científico y sistematizarlo en la práctica educativa.

En los momentos actuales la Dirección Provincial de Educación de la provincia de Pinar del Río extiende y experimenta las nuevas formas organizativas de trabajo, haciendo énfasis en el trabajo en red. A pesar de que el MINED concibe el trabajo metodológico en función de la preparación de la asignatura en red como elemento organizador y dinamizador del proceso docente educativo, este no logra la efectividad deseada en el tratamiento didáctico de los contenidos biológicos en toda la red escolar, aun así está bien delimitada la red escolar en cada consejo popular, los nuevos planes y programas de estudio favorecen la verticalización de los contenidos de célula en la asignatura de Biología, las orientaciones metodológicas constituyen una guía para el trabajo con contenidos de célula en la asignatura de Biología, a partir de la verticalización del contenido.

En visitas realizadas a centros se evidenció que no se aprovechan las potencialidades de las instituciones y especialistas de la comunidad para el desarrollo de la concepción curricular en los contenidos de célula, no se potencia el vínculo entre los diferentes niveles de educación y los participantes en las actividades metodológicas no desarrollan tareas o actividades previamente orientadas a partir de sus potencialidades o debilidades.

Aún cuando se conoce desde la teoría, qué es el trabajo en red y las potencialidades que ofrece para el perfeccionamiento del trabajo metodológico, los directivos y docentes no logran en la práctica desarrollar un sistema de actividades metodológicas que desde la red favorezca la preparación metodológica de la asignatura de Biología y dentro de ella la concepción curricular de los contenidos de célula.

Cabe entonces preguntarse ¿Cómo perfeccionar el proceso de preparación de la asignatura Biología, en concepción de red, en la provincia de Pinar del Río?

El concepto Trabajo Metodológico (TM) fue abordado por múltiples investigadores durante las tres últimas décadas del siglo XX, entre los cuales se destacan especialistas del MINED (1974, 1977, 1999 y 2000), García (1989); Díaz (1998); Ferrer (1999); Rico (1999) y Rizo (2000); entre otros.

El TM también ha sido abordado en este siglo y sobre él han profundizado: Pérez (2001); Rico (2002, 2004 y 2008); Sierra (2004); Leyva (2005); Romero (2006); Mesa y Salvador (2007); Pérez (2007 y 2008), Soto (2009); especialistas del MINED (2012); McPherson, (2012 y 2013), por solo citar algunos ejemplos. Particularmente durante el último quinquenio, fue estudiado por

58 UNESUM-Ciencias. Publicación cuatrimestral. Vol. 6, Año 2022, No. 1 (Enero - Abril) 
Caballero (2013), especialistas del MINED (2014); Cabrales (2015) y Amador (2016), entre otros.

En nuestro país se introduce este término con el Plan de Perfeccionamiento del Sistema Nacional de Educación (1975) y que coincide con la creación de las escuelas de apoyo, cuya función era servir de centro metodológico al trabajo del resto de las escuelas del país, aunque ya existían desde el curso escolar 1973-1974. En sus inicios el trabajo se encaminó a perfeccionar la labor diaria de los dirigentes de las escuelas. El objetivo de esta primera fase consistió en abordar aspectos organizativos y en la determinación precisa de las necesidades individuales para lograr una verdadera dirección colectiva en la escuela como forma científica de gestión escolar en las condiciones del socialismo. La creación de estas escuelas permitió tomar una serie de medidas encaminadas no solo a poner al descubierto las deficiencias en el trabajo del maestro para ayudarlo, sino también para encontrar los mejores métodos y procedimientos del trabajo docente y divulgarlo en el colectivo de maestros.

Como elementos proceso de perfeccionamiento, a partir del curso escolar 1976-1977 comienzan a desarrollarse los seminarios para dirigentes, metodólogos, e inspectores de las direcciones provinciales y nacionales de educación con el propósito de elevar su preparación para dirigir el proceso docente educativo.

A partir de este momento se aborda conceptualmente el trabajo metodológico, concibiéndose como "la actividad paulatina encaminada a superar la calificación profesional de los maestros, profesores, dirigentes de los centros docentes para alcanzar el objetivo de garantizar el cumplimiento de las tareas planteadas ante el sistema de educación en una etapa de su desarrollo" ( Lebedev, 1975) En esta definición se reconoce el trabajo metodológico como una actividad y se destacan dentro su objeto y su objetivo.

La complejidad y naturaleza de los problemas en la educación cubana requieren de soluciones con un enfoque más integral y multifacético, que demandan de una transformación en el funcionamiento de las instituciones y modalidades educativas. El proceso de experimentación pedagógica de las nuevas formas de trabajo de las instituciones y modalidades educativas que se desarrolla desde 2014 en seis provincias del país, tiene entre sus peculiaridades metodológicas, el acompañamiento de las estructuras de dirección de los diferentes niveles, lo que ha permitido modelar en la práctica determinados procederes metodológicos, válidos para el quehacer de estos equipos en el cumplimiento de las altas exigencias de su encargo social. Los cambios a los que se aspiran, se ajustan al desarrollo actual de la sociedad cubana y a la búsqueda de mecanismos de autorregulación del proceso educativo con la participación de los diferentes niveles y tipos de educación, como requiere la sociedad que construimos.

\section{En el Reglamento del TM del MINED No. 200/2014, Capítulo Generalidades.}

Capítulo V Direcciones y formas del TM. Artículo 55. La preparación de la asignatura o del área de desarrollo (Preescolar) es el tipo de trabajo docente - metodológico en el que participa el docente y el colectivo pedagógico, previo a la realización de la actividad docente, para garantizar la planificación y organización de los sistemas de clases y tareas del proceso educativo en Preescolar, con los elementos principales que aseguren la atención al diagnóstico del grupo y el desarrollo eficiente del proceso, teniendo en cuenta las orientaciones metodológicas del 
departamento, ciclo, grado o año al que pertenece y los objetivos del año de vida, grado o grupo, según corresponda. Esta tarea debe propiciar una adecuada orientación metodológica a los profesores a fin de garantizar que en cada ciclo, grado o departamento queden registrados, entre otros aspectos:

a) La determinación de los objetivos y los elementos básicos del contenido de cada clase o actividad.

b) La preparación de las clases o actividades a partir del análisis de los programas de asignaturas, de las video clases o tele clases, libros de textos y cuadernos de trabajo.

c) La adecuada utilización de los métodos y medios de enseñanza para asegurar el cumplimiento de los objetivos, priorizando los libros de textos, el software educativo, los cuadernos de trabajo y otros medios y fuentes audiovisuales.

d) El sistema de tareas (según el tipo de clases y diferencias individuales de los estudiantes), la orientación del estudio independiente y su salida en todas las formas organizativas del proceso educativo en Preescolar.

e) La determinación de las potencialidades educativas de la asignatura o áreas de desarrollo que contribuye a la formación integral.

f) Las vías para lograr la sistematización y consolidación de los contenidos de las asignaturas y áreas de desarrollo que preparen a los educandos para la aplicación de conocimientos y habilidades en la resolución de problemas.

g) La selección de una lógica del proceso educativo que propicie el desarrollo de la independencia cognoscitiva, de hábitos de estudio y de la creatividad.

h) La determinación de las actividades para el control, autocontrol y la evaluación.

i) Vínculo entre los contenidos de las diferentes asignaturas.

Los metodólogos en los diferentes niveles de educación planifican los sistemas de clases de las asignaturas para profundizar en el dominio del contenido y la didáctica en función de elevar la calidad de su preparación para las visitas de ayuda metodológica y las acciones de orientación que brinda a sus subordinados. Culminada la preparación se realizan talleres metodológicos para el análisis y discusión, en las direcciones nacional, provincial y municipal, según corresponda, de las clases preparadas y los elementos esenciales a tener en cuenta en la ejecución de la etapa. En el caso de los metodólogos de Primaria que son integrales planifican el sistema de clases de aquellas unidades y contenidos que requieren de una mayor profundización de la asignatura de la cual son responsables y posteriormente realizan intercambios en el equipo, para compartir los sistemas de clases de todas las restantes. El metodólogo de otras educaciones que atienda más de una asignatura, realiza el tratamiento metodológico de las unidades más complejas en cada programa y brinda las orientaciones generales para el resto del contenido. En Adultos se tiene en cuenta, además, las características de los docentes, fundamentalmente en Facultad Obrero Campesina.

En la red educativa, se plantea la educación desde el aprendizaje de igual a igual, basada en una reciprocidad multidimensional, donde dar y recibir depende del momento, de la capacidad y la posibilidad de cada miembro. Trabajar en red en la enseñanza supone incorporar diferentes

60 UNESUM-Ciencias. Publicación cuatrimestral. Vol. 6, Año 2022, No. 1 (Enero - Abril) 
maneras de concebir, compartir y aprehender los saberes, la multiculturalidad, la variedad de discursos, y la diversificación de los objetivos, además de fomentar el trabajo cooperativo y la evaluación progresiva. El trabajo en red viabiliza el empleo de diversas formas de trabajo metodológico, de superación e investigación, a través de la conformación de centros de recursos.

Colectivo de Autores ICCP / MINED 2018 Propuestas para la transformación de las instituciones y modalidades educativas. "el trabajo en red educativa es un sistema de relaciones para la interacción, colaboración, interdependencia y complementación de todos los implicados en: la implementación del proyecto educativo y el currículo institucional y de la modalidad; la conformación de los centros de recursos humanos, materiales, didácticos, metodológicos, organizativos y de nuevas tecnologías; la solución de los problemas identificados y la satisfacción de las necesidades y demandas de los participantes; y la materialización del Fin y los objetivos planteados para cada nivel educativo.

Para perfeccionar la preparación de la asignatura en concepción de red en los contenidos de célula se tiene en cuenta la verticalidad de los contenidos de célula en los niveles educativos: primaria, secundaria y preuniversitario en el Tercer Perfeccionamiento del Sistema Nacional de Educación. Los contenidos de célula se introducen en la primaria en la asignatura Ciencias Naturales en la Unidad \# 1" Los seres vivos: únicos y diversos en la naturaleza”, en la secundaria básica en séptimo grado la Unidad 2: El mundo vivo, ¿único o diverso? se realizan generalizaciones esenciales que serán aplicadas en el resto de las unidades, así como en grados posteriores y también se sistematizan y amplían. En 9no grado en la Unidad 2.El organismo humano y su salud, en esta se generalizan y se sistematizan estos contenidos.

En el preuniversitario, como nivel de profundización de los contenidos esenciales estudiados en los niveles precedentes, la disciplina Biología se centra en el estudio de la vida con un mayor nivel integrador y generalizador

\section{DESARROLLO}

\section{Materiales y métodos}

Por la importancia de las insuficiencias planteadas en la investigación, se utilizaron los siguientes métodos:

Enfoque de sistema: se utilizó en la elaboración de un sistema de actividades metodológicas para perfeccionar la preparación de la asignatura de Biología, dirigida a los contenidos de célula en concepción de red, al considerarla como un sistema con una adecuada estructura de los diferentes componentes que los integran.

El análisis documental tuvo como objetivo: analizar los diferentes documentos que norman el trabajo metodológico del tercer perfeccionamiento educacional y la enseñanza de la asignatura en los diferentes niveles educativos así como los planes de clases y orientaciones metodológicas de la asignatura de Biología.

Se tuvieron en cuenta durante la revisión de los documentos los siguientes aspectos:

1. Existencia de los documentos. 
2. Forma de orientar metodológicamente el trabajo con los contenidos de célula en los programas y orientaciones metodológicas.

3. Frecuencia establecida para el trabajo con los contenidos de célula.

4. Tratamiento que se le da a los contenidos de célula en los programas como en los libros de texto.

5. Existencia de actas de preparaciones metodológicas donde las actividades respondan al trabajo en red.

En los análisis realizados a los documentos normativos que direccionan el proceso de enseñanza y aprendizaje de la asignatura en los niveles educativos, se pudo constatar que, tanto en los programas como en las orientaciones metodológicas favorecen la verticalización de los contenidos de célula en la asignatura de Biología,

Aún cuando se conoce desde la teoría, qué es el trabajo en red y las potencialidades que ofrece para el perfeccionamiento del trabajo metodológico, los directivos y docentes no logran en la práctica desarrollar un sistema de actividades metodológicas que desde la red favorezca la preparación metodológica de la asignatura de Biología y dentro de ella la concepción curricular de los contenidos de célula.

Teniendo en cuenta los aspectos analizados, se propuso un sistema de actividades metodológicas, en concepción de red, para perfeccionar la preparación de la asignatura dirigida a los contenidos de célula en la provincia de Pinar del Río, como parte de la estrategia de la Dirección Provincial de Educación.

\section{Sistema de actividades elaborado.}

Objetivo General: perfeccionar la preparación de la asignatura en concepción de red, dirigidos a los contenidos de Biología.

Los métodos y procedimientos utilizados propiciaron perfeccionar la preparación de la asignatura en concepción de red con la participación de los maestros de cada grado de los diferentes niveles educativos, además profesores retirados, y padres trabajadores del sector de la salud invitados.

Se emplearon diferentes medios que propiciaron la interacción de los participantes, el contenido que se seleccionó estuvo en función del logro de los objetivos referidos y permitieron que se descubrieran en ellos la funcionalidad comunicativa de los medios empleados por los autores.

En el desarrollo de las actividades en la preparación de la asignatura se tuvo en cuenta la necesidad lograr la consulta de las orientaciones metodológicas, libros de texto y planes de clases en los que se abordan los contenidos de célula, ya que tienen potencialidades para lograr el trabajo en la red educativa.

Estas preparaciones de la asignatura se caracterizaron por ser flexibles y dinámicos, flexibles porque su desarrollo se adaptó a las condiciones de cada escuela y dinámico porque se utilizaron varias formas de darle respuesta a cada actividad para impartir el contenido.

Es bueno subrayar que al ser dirigido a profesores el ejercicio que buscan actualizar sus conocimientos para poder asumir con mayor éxito los retos de los nuevos programas, la integración didáctico-metodológica del contenido fue un principio que no pudo perderse de vista.

62 UNESUM-Ciencias. Publicación cuatrimestral. Vol. 6, Año 2022, No. 1 (Enero - Abril) 


\section{Resultados y discusión}

Con la realización del sistema de actividades metodológicas en concepción de red, se pudo comprobar que se logró elevar el nivel de los profesores en cuanto a dominio y conocimiento, además de lograr la verticalización de los contenidos de célula en cada grado de los niveles educativos, lo cual contribuyó a perfeccionar la preparación de la asignatura con una mayor calidad.

Se fortaleció el trabajo de los planes de clase y el tratamiento metodológico de las clases de los contenidos de célula; se manifestaron criterios positivos en torno a la preparación de la asignatura y se desarrollaron habilidades asociados a los contenidos de célula.

\section{CONCLUSIONES}

El trabajo metodológico realizado se concretó en un sistema de actividades metodológicas que contribuyó al perfeccionamiento de la preparación de la asignatura en concepción de red. Para la puesta en práctica del sistema de actividades se realizaron acciones como: diagnosticar a los docentes y personal no docente a participar. Los métodos aplicados permitieron constatar el estado actual de la preparación de la asignatura en concepción de red, al corroborar que presenta insuficiencias.

\section{REFERENCIAS BIBLIOGRÁFICAS}

Audesirk, Audesirk y Byers. Biología, la vida en la Tierra Octava edición. Pearson Education, México, 2008.

Acosta Sariego, José R. Bioética desde una perspectiva cubana. Publicaciones Acuario, Centro Félix Varela, La Habana, 2007 (edición digital)

Calzado D. y Fátima Addine. Didáctica, currículo e interdisciplinariedad en el preuniversitario. Maestría en Ciencias de la Educación, Mención Educación Preuniversitaria, Editorial Pueblo y Educación, 2006.

Colectivo de autores, Orientaciones Metodológicas. Biología 4. Decimo Grado. Marzo 2019.

Colectivo de autores, Orientaciones Metodológicas. Biología 5. Onceno Grado. Marzo 2019.

Colectivo de autores, Orientaciones Metodológicas. Biología 6. Decimo Grado. Marzo 2019.

De Robertis, E.D.P. y E.M.F. de Robertis. Biología celular y molecular. 12. Edición. La Habana, 1998.

Domínguez G., Laura. Psicología del desarrollo. Problemas. Principios y Categorías. Editorial de Asesoría y Servicios S.A. de C. V. Tamaulipas. México, 2006.

Guanche Martínez, Adania. Fundamentos de la enseñanza problémica en las Ciencias Naturales.

Hernández, Pedro A. Metodología para el trabajo en seminario. Editorial Academia, La Habana, 1999.

ICCP Bases Generales para el Perfeccionamiento del Sistema Nacional de Educación. Noviembre del 2011.

Jardinot Mustelier, Luis Roberto. Creatividad y Modelación: su integración didáctica en la formación de conceptos científicos. En: El desarrollo de la creatividad. Teoría y práctica en la educación. Editorial Pueblo y Educación, 2009.

LACUEVA, Aurora. «Recursos para el aprendizaje y desescolarización en la escuela básica». Col. Cuadernos de Educación, No. 132. Caracas: Laboratorio Educativo, 1985.

LACUEVA, Aurora. «Las Ciencias Naturales en la Escuela Básica». Col. Procesos Educativos, No. 10. Caracas: Fe y Alegría, 1996.

(C) Universidad Estatal del Sur de Manabí. Jipijapa, Ecuador. 
LACUEVA, Aurora. «Retos y propuestas para una didáctica contextualizada y crítica». Educación y Pedagogía. IX(18): 39-82, 1997.

Ministerio de Educación (MINED). (1999). Resolución Ministerial 85/1999. Precisiones para el desarrollo del trabajo metodológico. La Habana: Impresiones ligeras MINED.

Pacheco, R.; Alonso, S. H. y Mena, J. A. (2018). Génesis y evolución del STM como parte del sistema de trabajo en Cuba. Mendive, Vol. 16, No 2, 313-328.

Salcedo, Inés y otros. Didáctica de la Biología. Editorial Pueblo y Educación, La Habana, 1992.

Zilberstein Toruncha, J.; et al. 1991. Biología 5: Duodécimo grado: Libro de texto. Parte 1. Editorial Pueblo y Educación, La Habana.

64 UNESUM-Ciencias. Publicación cuatrimestral. Vol. 6, Año 2022, No. 1 (Enero - Abril) 